\title{
Innovative technologies in brick masonry restoration of architectural monuments
}

\author{
Sergey Chernyshev ${ }^{1}$, Igor Rubtsov ${ }^{1}$, and Elena Elmanova ${ }^{1, *}$ \\ ${ }^{1}$ Moscow State University of Civil Engineering, 26 Yaroslavskoe Shosse, Moscow, 129337, Russia
}

\begin{abstract}
The facade walls of ancient Russian landmark buildings built of brick or natural stone, are generally flat, have a complex relief created in order to obtain an effect of light and shade in side lighting. In the restoration, reconstruction, as well as new construction in retro style, this relief should be reproduced. The report describes the "flat" relief of the 19th century's landmark building - the church in the Abramtsevo estate near Moscow. The surface was scanned with Trimble S6 electronic tacheometer with subsequent processing by 3D Reshaper Survey Bundle program and mathematical description of digital data using the theory of random functions. It was established that the wall surface can be modeled by a nonstationary random function with two harmonics. To realize a model in the masonry of the restored or reconstructed wall, the basic technology was proposed, which embraced techniques of researching, designing and reproducing the surface of an uneven facade wall.
\end{abstract}

\section{Introduction}

Today, Russia faces large-scale restoration and reconstruction of historic buildings. Buildings destroyed during the Soviet era have been and are being erected. In downtown Moscow, the Cathedral of Christ the Savior was built, in Yaroslavl - the main cathedral of the city. The construction of a completely destroyed cathedral in Kostroma is underway now. It has also been planned to restore a section of the fortification wall of the second defensive ring around ancient Moscow - a wall of Kitai-Gorod in Kitaigorodsky Passage in downtown Moscow. In many regions of Russia, ruined churches, a considerable part of which has been lost, are being restored. The fortification wall in Tula has been restored; the restoration of Kostroma's walls is underway. The work is carried out by Russian and foreign companies that have public licenses for restoration work. They are guided by the restoration standards [4], which do not provide for the reproduction of a complex surface in the generally flat wall. Unevenness of the wall surface is often mistaken for a masonry defect due to poor workmanship.

In the restoration practices, one has to deal with cases where new wall sections are made with smooth, "better" than the ancient surfaces. In fact, the uneven wall surface made by old masters is an element of facade decoration. In this way, they created a play of light and shadow, when the wall was lit laterally. The complex surface includes waves with different

${ }^{*}$ Corresponding author: eleosu@yandex.ru 
range-frequency properties. They are not created accurately, but with significant random deviations from the average value. Due to this, the face of the wall changes significantly from place to place and throughout the day. When illuminated from different sides, the plane of the wall looks different. Its look is different for different parts of the wall. This can also be relevant for modern buildings that often have large and undivided wall surfaces. Ancient architects were much closer to nature than we are. In their architecture, they reproduced images of nature, such as waves, arable lands or fields. They reproduced waves in ornaments and in wall surfaces. Natural objects with waves feature diverse harmonics. Large waves on the water have small ripple. Moving lake or sea waves with a certain wind are approximately equal, yet differ in size from the average value. Their length and range can be described statistically. Russian architects saw waves not only on the water. Their fields, unlike rice fields, were not flat. They were hollow wavy, and the furrows from the plow left a wave with different harmonics.

This paper explores the unevenness of the wall surface of the historic building and offers a technology of reproducing its surface in the course of restoration. We affirm that the complex relief is a deliberate way of decorating the wall plane and should be reproduced during restoration similar to the surviving parts of the restored monument, and if a lost monument is to be reconstructed - using the structures of the same style and epoch as the reconstructed one. To reproduce the relief, it must first be captured and described. This is done in this paper mathematically using the standard geodetic equipment for digitizing an object with subsequent processing by conventional computer programs.

\section{Research subject}

Our research subject is monument of architecture - a manor church in the museum-reserve Abramtsevo near Moscow built according to V. M. Vasnetsov's and V. D. Polenov's project in 1882. Before working on the project, the authors studied samples of the ancient Russian architecture from different regional schools by publications and on-site [3]. The Church of the Transfiguration of our Savior on Nereditsa Hill (1198) near Veliky Novgorod was chosen as a benchmark, but the construction included elements of the décor borrowed from Yaroslavl, Moscow, Vladimir masters. The relief of the walls was created similar to the wall relief of the Church of the Transfiguration of our Savior on Nereditsa Hill in Veliky Novgorod, which was available to the authors of Abramtsevo church for study before the restoration in 1904, and destroyed during the WWII, recreated in 1958 and included in the World Heritage List by the decision of UNESCO in 1992, despite the fact that it was rebuilt. In this regard, the relief of the walls of Abramtsevo church may be of interest to researchers of the history of architecture as a copy of the lost monument.

The church of Abramtsevo is one-domed with a belfry (Figure 1), built of red brick with white stone window frames and portal columns. The surfaces of the facade walls and buttresses, just like the walls of monuments in Veliky Novgorod, are uneven. At first glance, this is unkempt masonry. However, there are no grounds to assume that the complex unevenness of the wall resulted from poor workmanship. The church was built in the estate of S. I. Mamontov, a millionaire, who, at that time, built hundreds of kilometers of railroads and numerous railway stations, whose walls, being in sync with the aesthetics of the 19th century, were made perfectly flat. S. I. Mamontov could invite the best masters for the construction of the church in his estate. Just like his friends - Mamontov art circle, he wanted to build a church in retro style. Thus, they carved white stone patterns themselves and instructed even children to have chipped and asymmetric surfaces similar to ancient structures. But the façades have never been plastered. This is evidenced by numerous photographs and picturesque images of the church throughout all decades of its existence [2]. 
The surface of the masonry was just coated with whitewash. During the latest restoration, the same coating was applied. The original coating, as well as the coating during the restoration, was made with a gloved hand. The rough masonry was smoothened manually. Still, the complex relief of the walls was well preserved, somewhat smoothed out in detail. Groups of bricks stand out from the façade surface lit by oblique sunrays. To the right of the carved column, the portal wall profile is clearly visible. In the lower part, it deviates from the vertical line towards the column.

Along with the unevenness of the wall surface, the architecture of the church has the second feature typical to ancient buildings of Veliky Novgorod. There are many elements of asymmetry in it. The study of asymmetry was not our task.

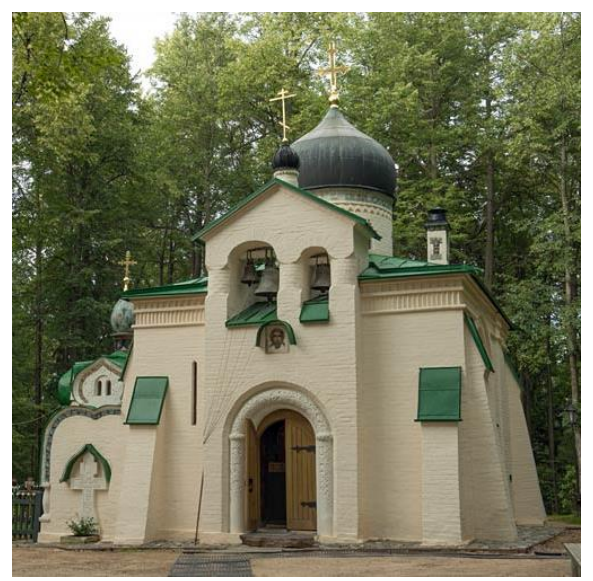

Fig. 1. The western façade of the church in the museum-reserve Abramtsevo near Moscow. Built in 1882. Photo of 2015.

\section{Research method}

The required architectural measurements were made directly on the monument, with the permission of the museum's administration. The key part of the work was the capture of the relief of the monument's three flat walls. To explore the relief of the walls, the laser scanning method was first used. The measurements were made in January 2017 using an electronic tacheometer Trimble S6 (Figure 2). The device captures the surface with an accuracy of \pm 1 $\mathrm{mm}$ at an interval between scanning points up to $1 \mathrm{~cm}$; the set of digital data was processed using 3D Reshaper Survey Bundle program.

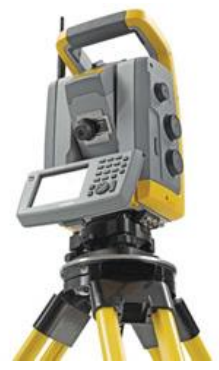

Fig. 2. Trimble S6 tacheometer.

Based on the data obtained during the scanning of the building, with the help of standard software for statistical processing of random function realizations, profiles of a brick buttress, 
horizontal and vertical wall profiles were constructed. Using AutoCAD, the deviations of the wall surface from the baseline value of the plane were measured. Here, the surface of the wall, generalized to the plane, was taken as the coordinate plane XY. The YZ plane is perpendicular to the wall surface and is strictly vertical. The $\mathrm{XZ}$ plane is perpendicular to the wall surface and is almost horizontal with the deviation from the horizon equal to a slight slope of the wall due to the pyramidal shape of the structure.

\section{Results}

The realizations of the random function describing the wall surface were taken along the sections parallel to the coordinate planes $\mathrm{XZ}$ and $\mathrm{YZ}$. The deviation from the wall plane characterizes the value of the $\mathrm{Z}$ coordinate.

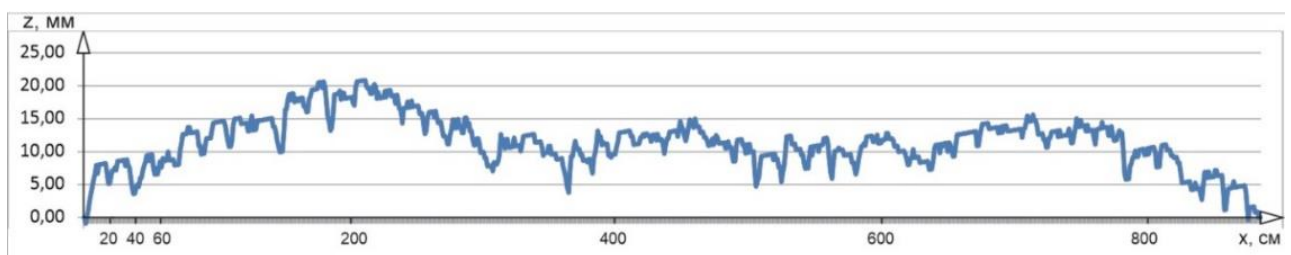

Fig. 3. Deviation of the northern wall surface from the plane for the horizontal profile No. 4.

We take the surface of the wall for the realization of a stationary random function in a three-dimensional space [1]. The graph in Figure 3 is a flat horizontal section of a random surface [1]. Apparently, it has flat tops with sharp narrow dives. The range of the short wave is about $5 \mathrm{~mm}$. However, the waves are not identical. In some places, the dives are only 1-2 $\mathrm{mm}$, sometimes reaching seven and even ten millimeters. The flat tops correspond to the surface of individual masonry bricks, and the dives between them - to the masonry seams. There is also a second long-wave harmonic in the unevenness of the wall. The wavelength here ranges from 1 to 3-4 m. For the cross section of the random surface shown in Figure 3, the autocorrelation function is calculated and its graph is constructed (Figure 4). The ordinate axis shows the values of the autocorrelation function, the abscissa axis - the distance in centimeters between the correlated values. To measure the autocorrelation function, 800 measurement points were used. The measurements showed the closest link between the values spaced by $5 \mathrm{~cm}$ or less, a close relationship for values up to $10 \mathrm{~cm}$. At these distances, the wall surface in the horizontal section consists of one brick. Further, the connection decreases, and at a distance of 150 to 200 centimeters, the autocorrelation ratio becomes negative, indicating that it is half the wavelength. Despite the small values of the autocorrelation ratio, the connection should be deemed significant due to the large number of experimental points. At a distance of $300 \mathrm{~cm}$, the graph of the autocorrelation function turns positive, indicating that the length of the large wave on the wall surface is $300 \mathrm{~cm}$ on average. The small values of the autocorrelation ratio show that surface waves, while generally similar, vary greatly in magnitude, that is, randomness in the described process is high. The latter excludes the modeling of the surface during restoration by any deterministic function.

The graph of the autocorrelation function for the vertical section of the inclined buttress surface was also constructed (Figure 5). In general, it does not differ from the graph for the horizontal section of the wall (Figure 4). It features no second escape of the autocorrelation function to the negative area, which is due to the low height of the buttress. There is only one dive between the surface elevations. The similarity of graphs shows one random surface modeled on the buttress and on the wall. 


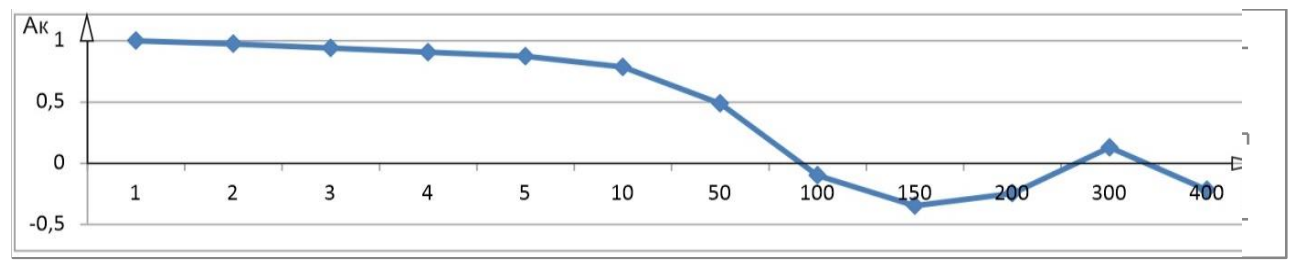

Fig. 4. Autocorrelation function for the horizontal section of the northern wall.

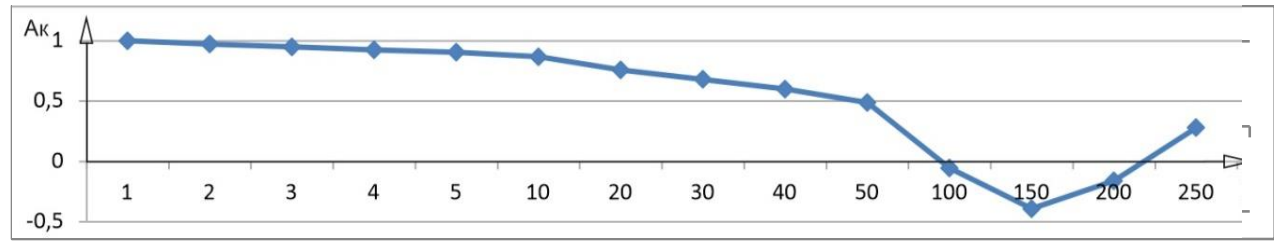

Fig. 5. Autocorrelation on the profile No. 1 (vertical profile -400 points).

The wall surface is a random function different from "white noise", from a random value characterized by a lack of connection between neighboring values in the field. The wavelength fits in the dimensions of the monument along the length and height of the facade a number of times, two or three times.

The point cloud obtained through the scanning of the northern wall of the Church of Our Savior Not Made by Hands in Abramtsevo was also processed by 3D Reshaper Survey Bundle program. The layout of the wall surfaces (Figure 6) and the corresponding layout of the buttress façade surface - 3D images of the reliefs - were also obtained. The third dimension in the figure plane is shown in color. As is customary in geodesy, the relief is depicted by horizontal lines - lines of equal heights $\mathrm{Z}$ over the coordinate plane XY. For 00 height a plane is taken, from which the wall relief equally deviates to the positive and negative areas. This is the average position of the wall surface. The section of the wall relief by planes parallel to the XY coordinate plane is made with $10 \mathrm{~mm}$ interval. The elevation of the relief above the coordinate plane is shown by color boundaries. Cold colors - green, light and dark blue - show wall protrusions. Warm colors - yellow, red and gray - denote cavities. The boundaries between the colors correspond to the following values of the surface excess over the XY plane: gray - red $-20 \mathrm{~mm}$, red - yellow $-10 \mathrm{~mm}$, yellow - green $00 \mathrm{~mm}$, green - light blue $+10 \mathrm{~mm}$, light blue - dark blue $+20 \mathrm{~mm}$. Thus, in the gray area there are points immersed in $\mathrm{Z}$ below the average position of the wall by $20 \mathrm{~mm}$ or more, but not more than $30 \mathrm{~mm}$. In the blue area, there are points raised above the middle wall surface by $20 \mathrm{~mm}$ and more, but not over $30 \mathrm{~mm}$. The total scope of surface does not exceed $60 \mathrm{~mm}$.

The wall map (Figure 6) shows macro- and microrelief. Considering the macrorelief, in the upper right corner and on the right along the bottom of the wall, we see gray-red areas of cavities, where the wall surface goes 30 and more millimeters deep below the coordinate plane. The central and left parts of the map are dominated by marked light and dark blue elevations of the wall surface, sometimes exceeding $20 \mathrm{~mm}$ above the coordinate plane. In the vertical section on the fragment under consideration, the wall has three cavities and two protrusions between them. The wavelength is about $0.7-0.9 \mathrm{~m}$ at a range of $0.05 \mathrm{~m}$. In the horizontal section, the surface wave is less pronounced, but is present as transverse uplifts in a horizontally elongated cavity. The distance between them is about 1.5-1.9 $\mathrm{m}$ with the same range. 


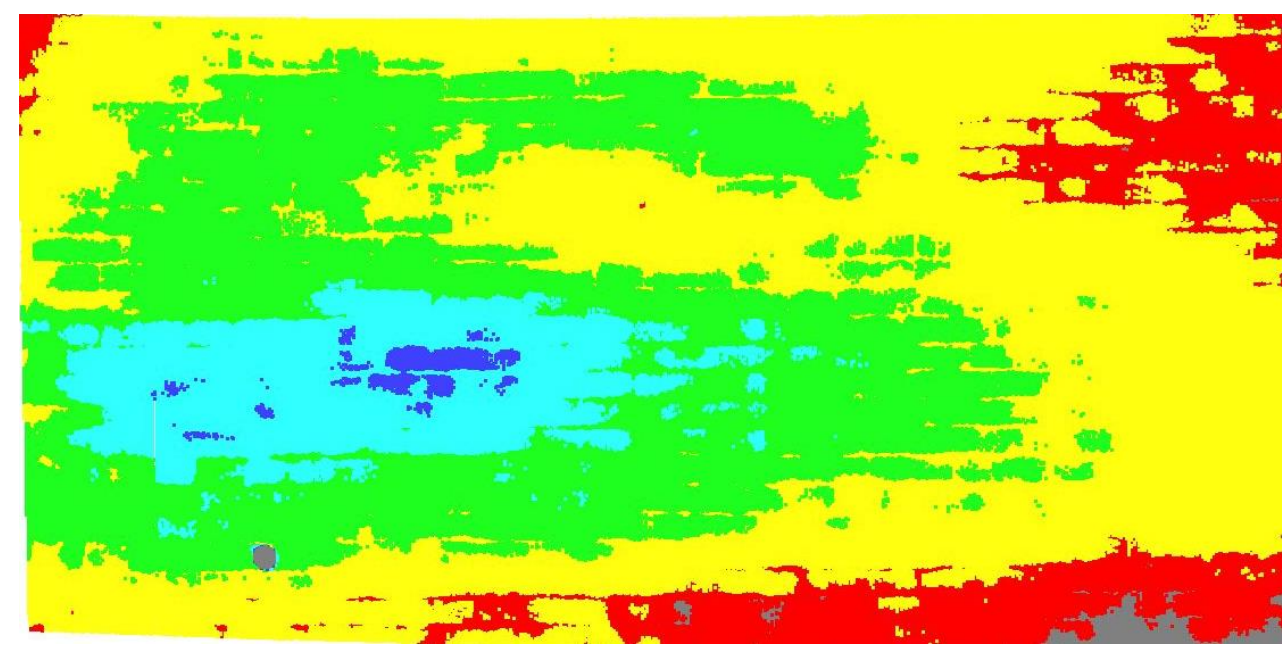

Fig. 6. Map of deviations of the wall relief from the plane. Fragment of the northern wall of the church in the museum-reserve Abramtsevo, $1.44 \times 3.27 \mathrm{~m}$.

The boundaries of the macrorelief shapes indicated by the transition from one color to another are very unclear and ragged. At color borders, many small protrusions and narrow apertures are seen. This is microrelief of the wall surface with the protrusions of individual bricks over neighboring bricks and with gaps in the place of seams filled at different depths with a binder whitewash solution. Far from color boundaries, this microrelief is not readable, although it is present judging from visual observations and profiles processed using the method of random functions. The range of the microrelief does not reach $10 \mathrm{~mm}$. The horizontal and vertical wavelength of the microrelief corresponds to the size of the brick with the added width of the seam. In the vertical section, the wavelength is $0.065 \mathrm{~m}$; in the horizontal section, waves of $0.13 \mathrm{~m}$ and $0.26 \mathrm{~m}$ are observed.

The relief described by the scanning is random. To reproduce it during restoration or reconstruction, or when creating a copy of the monument, one should use a map like this (Figure 7), or profiles for each row of masonry. The profile indicates the position of each brick relative to the coordinate plane. Building the walls, a bricklayer should lay each brick of the row in accordance with its indentation from the coordinate plane designated by a cord.

\section{Conclusions and technological recommendations}

The facades of the explored historic buildings have rough walls. They completely preserved the relief created by the builders with the continuous monitoring by V. M. Vasnetsov, so there is no doubt about their authenticity. The relief is modeled similar to the walls of the Church of the Transfiguration of our Savior on Nereditsa Hill in Veliky Novgorod.

The wall surface can be approximated by a random function in the Cartesian coordinates $X Y Z$ system with a constant mathematical expectation of the wall deviation along the $Z$ axis from the XY plane. The nature of $z$ value change is not entirely random. The neighboring values of $\mathrm{z}$ are very close within the area occupied by one brick on the wall surface, are similar for an area occupied by three to five bricks, but then $\mathrm{z}$ values diverge. The wall surface has waves ranging from 0.7 to $1.9 \mathrm{~m}$ with a wave height of up to $50 \mathrm{~mm}$. On the surface of a large wave, there are small waves, secondary in magnitude. The complex wall surface was created by architects with special purposes. It should be recreated during the restoration and reproduction of monuments with rough wall surfaces, and there are plenty of such 
monuments in Russia. It should be recreated for a newly constructed temple similar to that in Abramtsevo (there is information that a church similar to Abramtsevo can be built).

There are plenty of monuments with rough walls in Russia. Reproducing wall unevenness is a typical task in restoration, reconstruction, recreation of monuments of Old Russian architecture and imitation of old models in new construction. The task cannot be solved by creating a random protrusion of individual bricks from the plane of the wall. It cannot be solved by creating a pattern, along which a series of bricks will be laid out, since the change in the height of the jut has both a random and a regular component. The established fact of describing the surface by a random function requires the following order of designing this surface during restoration: 1) measure the unevenness of the facade wall, which is best done by laser scanning; 2) approximate the resulting digital data set through building topographic plans and obtaining maps of preserved wall sections; 3 ) print maps of the wall deviation along $\mathrm{Z}$ from the generalized plane of the wall XY; 4) on the map, build the wall profiles for each row of bricks; 5) lay a wall with a shift from the cord in accordance with the profile of the row, sometimes approaching the cord, sometimes moving away from it. These procedures, which seem burdensome, can be quickly and accurately performed when measuring and designing restoration with modern measuring and computing electronics and the corresponding software available in geodesy. Given the random nature of the wall surface, the requirements for the accuracy of laying each individual brick can be low compared to the accuracy of the shape masonry or ideally flat wall.

In modern construction, brickwork is often included in the interior imitating ancient buildings. The technique of making wall irregularities proposed here can be used in modern construction.

The work was supported by HEXAGON Geosystems. The authors are especially thankful to the scanning engineer Alexander Yuryevich Solopov.

\section{References}

1. E.S. Venttsel, Probability theory (Nauka Publishing House, Moscow, 1964)

2. E.V. Paston, Abramtsevo. Art and life (Iskusstvo Publishing House, Moscow, 2003)

3. N.V. Polenova, Abramtsevo. Memories (M.\& S. Sabashnikovy Publishing House, Moscow, 1922)

4. TSN 2001.7-3. Territorial estimates for Moscow. Chapter 7. Restoration work on monuments of history and culture. Collection 3. Restoration and reconstruction of brick masonry (Moscow, 2006)

5. SSN-3-84. Collection of estimate norms and separate rates for restoration and repair of monuments of history and culture of Moscow. Restoration and reconstruction of brick masonry (Moscow, 1984)

6. F. Chiabrando, Remote Sensing and Spatial Information Sciences 2-5, 97 (2014) 